\title{
Short-Term Forecasting Management Research of Deep Horizontal Displacement of Slope Soil Based on ARIMA Model
}

\author{
Kai Yan', Jiaye $\mathrm{Wu}^{2 *}$, Yingqian Zhang3, Lu Yang ${ }^{4}$ \\ ${ }^{1}$ School of Management of Sichuan University of Science \& Engineering, Zigong, China \\ ${ }^{2}$ Sichuan Sheng Tuo Testing Technology Co., LTD2, Zigong, China \\ ${ }^{3}$ School of Civil Engineering of Sichuan University of Science \& Engineering, Zigong, China \\ ${ }^{4}$ School of Civil Engineering of Northeast Forestry University, Harbin, China \\ Email: ^1411725547@qq.com
}

How to cite this paper: Yan, K., Wu, J.Y., Zhang, Y.Q. and Yang, L. (2019) Short-Term Forecasting Management Research of Deep Horizontal Displacement of Slope Soil Based on ARIMA Model. Open Access Library Journal, 6: e5496.

https://doi.org/10.4236/oalib.1105496

Received: May 23, 2019

Accepted: June 8, 2019

Published: June 11, 2019

Copyright $\odot 2019$ by author(s) and Open Access Library Inc.

This work is licensed under the Creative Commons Attribution International License (CC BY 4.0).

http://creativecommons.org/licenses/by/4.0/

cc) (i) Open Access

\begin{abstract}
The forecasting of deep horizontal displacement of slope soil is an important part of slope deformation monitoring, which has important guiding significance for the prevention of slope safety accidents. The historical data of deep horizontal displacement of slope soil are non-stationary time series with both random growth and time-varying fluctuation, and ARIMA model is suitable for forecasting such time series. In this paper, 648 historical data of deep horizontal displacement of soil were selected as the original sequence of empirical analysis, and forecasted the law and trend of displacement change by establishing ARIMA model. The results of empirical analysis showed that the effect of short-term static forecasting was good, which could provide useful reference for managers of slope quality safety govern slope and analyze the slope stability.
\end{abstract}

\section{Subject Areas \\ Civil Engineering}

\section{Keywords}

Engineering Management, ARIMA Model, Short-Term Forecasting, Deep Horizontal Displacement of Slope Soil

\section{Introduction}

Slope stability has always been an important research content of slope engineering [1]. In recent years, despite the rapid development of China's social economy 
and the rapid growth of large-scale rock mass engineering, a large number of slopes have been formed in the construction of railway, highway and other projects in mountainous areas. Landslides have now become one of the three major geological disasters in the world along with earthquakes and volcanoes [2] [3]. For example, in 1963, a landslide occurred on the slope of the way on reservoir in Italy, killing more than 2500 people; in 1970, about $25 \mathrm{~km}$ west of the city of Chimbote, Peru, a 7.7-magnitude earthquake occurred, which triggered a large number of landslides and collapses, resulting in a total of 67,000 deaths [4]. In June 2014, a landslide occurred between Lianghekou and Zhenzijie station area of the Chongqing-Guizhou railway, resulting in the detour or suspension of 29 passenger trains; in November 2014, a landslide occurred on the Xunyang to Chongxi upbound line of Xiangyu railway in Shaanxi province, causing the derailment of $1-12$ carriages of the 75,228 train, resulting in the death of two drivers and the delay of some trains [5].

It can be seen that for natural slope collapse, landslide, etc., or man-made slope instability caused by human engineering activities, these geological disasters have caused huge losses to economic construction and people's property [6]. Therefore, it is of great significance to seek a scientific management method to prevent slope accidents.

However, slope engineering is an uncertain, nonlinear and complex system [7], and there are a variety of slope safety monitoring technologies at home and abroad. For example, in 2010, Pieraccini, Barla, Gischig et al. first used GB-In SAR to monitor and study the deformation of slope [8] [9] [10]; in 2012, Ruan Zhixin used the inclinometer to monitor the expressway slope and proved the correctness of the monitoring [11]; in 2013, Wang Zhiyong used In SAR technology to monitor the landslide in Fangshan area of Beijing [12]; in 2015, Xu Maolin used TM30 to carry out a monitoring experiment on the slope displacement of an open pit mine in Anshan city, realizing automatic monitoring [13], etc. Most of these slope engineering monitoring technologies are used to monitor the slope deformation, so it is concluded that the slope deformation is very important to the slope stability analysis. Therefore, this paper attempts to start with the deep horizontal displacement of soil in slope deformation monitoring, builds ARIMA model, and uses EViews to forecast and empirically analyze the deep horizontal displacement of soil.

\section{Forecasting Theory and Methods}

\subsection{Forecasting Theory of Deep Horizontal Displacement of Soil}

The forecasting of deep horizontal displacement series of soil mass refers to the estimation of the displacement value of a certain period or periods in the future by using historical data of the evolution of things, comprehensive consideration of various influencing factors and some scientific research methods. The time series of the known horizontal displacement value of deep soil is $\left\{H_{1}, H_{2}, H_{3}, \cdots, H_{T}\right\}$, to forecast the displacement value of 


$$
\begin{aligned}
& H_{T+1}, H_{T+2}, H_{T+3}, \cdots, H_{T+m} \text {, the formula is defined as: } \\
& \qquad \hat{H}_{T+1}, \hat{H}_{T+2}, \cdots, \hat{H}_{T+m}=f\left(H_{1}, H_{2}, \cdots, H_{T}\right)
\end{aligned}
$$

Among them, only doing the one-step forecasting, so the $H_{T+1}$ is estimated, which is called single-step forecasting; When $H_{T+m}$ and $m>1$ are forecasted, it is called $\mathrm{m}$-step forecasting. It is obvious that $\mathrm{m}$-step forecasting is composed of multiple single-step forecasting, that is, formula (1) can be written as:

$$
\begin{aligned}
\hat{H}_{T+1} & =f\left(H_{1}, H_{2}, \cdots, H_{T}\right) \\
\hat{H}_{T+2} & =f\left(H_{1}, H_{2}, \cdots, H_{T+1}\right) \\
& \vdots \\
\hat{H}_{T+m} & =f\left(H_{1}, H_{2}, \cdots, H_{T+m-1}\right)
\end{aligned}
$$

The purpose of forecasting research is to understand the future development state or trend of things. It is widely concerned because the current state of things may affect the future results. The appropriate forecasting method is applied to the forecasting of deep horizontal displacement of slope soil, and the Suggestions are provided for the slope quality and safety management, which is conducive to the analysis of slope stability and the prevention of slope safety accidents. Therefore, the forecasting of deep horizontal displacement of slope soil is a very important forecasting problem.

\subsection{Time Series Forecasting Analysis}

The method of time series forecasting is to regard the historical monitoring data of the deep horizontal displacement of slope soil as the time series of changes, and to forecast the trend and rule of the future evolution of things by building a reasonable time series model, see Figure 1. However, the time series forecasting method is in line with the randomness, time-variability and other characteristics of the deep horizontal displacement evolution of slope soil, and has a high short-term forecasting accuracy. At present, the commonly used time series analysis methods include autoregressive model (AR), sliding average model

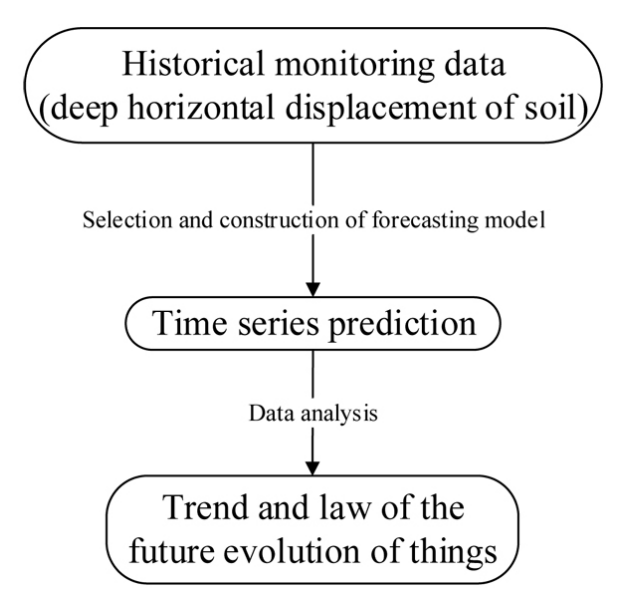

Figure 1. A analysis process of the time series prediction method. 
(MA) and autoregressive sliding average model (ARMA), etc., and their theoretical formula [14] is as follows:

The formula of $\operatorname{AR}(p)$ :

$$
x_{t}=\delta+\phi_{1} x_{t-1}+\phi_{2} x_{t-2}+\cdots+\phi_{p} x_{t-p}+u_{t}
$$

The formula of $\operatorname{MA}(q)$ :

$$
x_{t}=u+u_{t}+\theta_{1} u_{t-1}+\theta_{2} u_{t-2}+\cdots+\theta_{q} u_{t-q}
$$

The formula of $\operatorname{ARMA}(p, q)$ :

$$
\begin{aligned}
x_{t}= & \phi_{1} x_{t-1}+\phi_{2} x_{t-2}+\cdots+\phi_{p} x_{t-p}+\delta \\
& +u_{t}+\theta_{1} u_{t-1}+\theta_{2} u_{t-2}+\cdots+\theta_{q} u_{t-q}
\end{aligned}
$$

There are two forecasting methods: static forecasting and dynamic forecasting. Static forecasting refers to the forecasting based on the actual value in the original sequence, which can only be used after obtaining the real data. Dynamic forecasting refers to the forecasting of the first phase from the actual value, and then the first phase value is put into the original time series to forecast the value of the second phase together with it, and so on, but for long-term forecasting, it may produce cumulative error.

\section{Empirical Analysis of ARIMA Model Based on the Monitoring Value of Deep Horizontal Displacement of Slope Soil}

\subsection{Problem Description and Model Introduction}

In the long-term slope deformation process, the monitored horizontal displacement value of soil depth changes with the seasonal cycle and has a certain increase (or decrease) trend of non-stationary time series. Traditional forecasting methods, such as regression model and gray $\operatorname{GM}(1,1)$ model, are applicable to stationary time series, and the forecasting results for such values are not ideal [15]. And C. P. Box and G. M. Jenkins was first put forward the regression sum of moving average model (ARIMA model for short), is a non-stationary time series after $d$ first order difference tranquilization, again to get the stationary time series by using autoregressive $(\operatorname{AR}(p)$ process) and moving average $(\operatorname{MA}(q)$ process), and through the sample autocorrelation coefficient (ACF) and partial autocorrelation coefficient (PCF), and other data to establish the model of recognition, at the same time also put forward a set of modeling, estimation, inspection and control methods for the [16]. Therefore, it is suitable for forecasting time series problems with periodic fluctuations and trend growth (or decrease). Set $\left\{H_{t}\right\}$ as stationary time series and the mean value is zero, then the first-order autoregressive first-order sliding average model formula of $\operatorname{ARMA}(1,1)$ can be expressed as:

$$
H_{t}=\phi H_{t-1}+e_{t}-\theta e_{t-1}
$$

Therefore, the formula of $\operatorname{ARMA}(p, q)$ can be expressed as:

$$
H_{t}-\phi_{1} H_{t-1}-\cdots-\phi_{p} H_{t-p}=e_{t}-\theta_{1} e_{t-1}-\cdots-\theta_{q} e_{t-q}
$$


Formula (4) can be abbreviated as:

$$
\phi(B) H_{t}=\theta(B) e_{t}
$$

Among them, $e_{t}$ represents the white noise parameter, $t=1,2, \cdots, p ; \phi$ said regression coefficient; $\theta$ represents the regression parameter. In the model $\operatorname{ARIMA}(p, d, q), d$ represents the difference order. In slope monitoring projects, time series data of deep horizontal displacement of soil are generally unstable, and there are many ways to make the series stable. Difference is one of them, and the modeling process of ARIMA model is almost the same as that of ARMA.

\subsection{Build a Model}

The data of deep horizontal displacement of slope soil in this paper are obtained from the SQLsever database of Sichuan Shengtuo Detection co., LTD. The related slope engineering project is the ladder trough landslide monitoring project of Shuangma village, Shiguan township, Maoxian county. SQLsever database is a high performance and extensible relational database management system designed by Microsoft.

Due to the failure of data acquisition equipment and external environment, data acquisition at some time points is missing. Therefore, in order to reduce the forecasting error, a continuous and stable period of monitoring data was selected for the forecasting experiment.

Randomly selecting 500 - 650 data of a deep horizontal displacement monitoring point in the monitoring project. There are two reasons for the selection of 500 - 650: first, if too little data is taken, the information in the original sequence cannot be fully mined; and if too much data is selected, the sequence interval will be too long, making the early data have little influence on the later forecasting data and causing unnecessary errors. Second, a lot of related time series forecasting literatures are consulted. If the number of original series in the empirical analysis of quarterly data ( $m=4$, cycle four quarters a year) is between 50 and 100 , and the number of monthly data ( $m=12$, cycle for 1 year and 12 months) is between 250 and 350, the number of original series in the empirical analysis of time data ( $m=24$, cycle 24 hours a day) is between 500 and 650 .

In this paper, from 0 points on August 15, 2018 to 23 points on September 10, 2018, all the whole point data in the direction of "X axis" are selected to form the "H" data set and sequence $\left\{H_{t}\right\}$. The data amount is 504, as shown in Figure 2. As can be seen from Figure 2, "sequence $\left\{H_{t}\right\}$ is an obvious time series with deterministic trend and periodicity".

According to the above "three criteria", AIC, SC and HQ values with smaller values are better. Based on the unit root test results in Table 1, it can be judged that this sequence is a unit root process with no intercept term and no trend term.

It can be seen from Table 2 that the absolute value of the $t$-statistic value of the first-order difference ADF test is 18.5774, which is much higher than the $\mathrm{t}$-statistic value of 1.9413 when the significance level is 0.05 , so the null hypothesis 


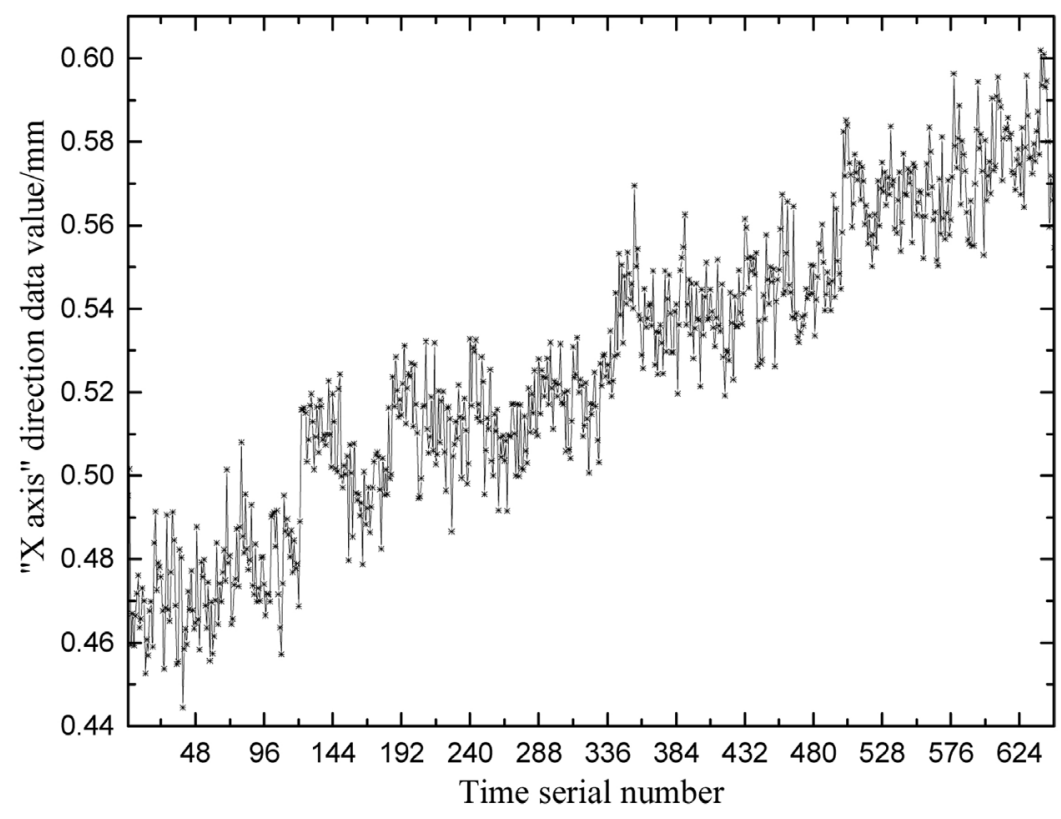

Figure 2. The sequence diagram of the " $\mathrm{H}$ " dataset.

Table 1. The unit root test of the first-order difference sequence.

\begin{tabular}{cccc}
\hline ADF tests the category & AIC & SC & HQ \\
\hline Intercept, Trend & -6.3234 & -6.2818 & -6.3073 \\
Intercept & -6.3263 & -6.2916 & -6.3129 \\
No intercept, No trend & -6.3284 & -6.3006 & -6.3176 \\
\hline
\end{tabular}

Note: AIC, also known as AIC information criterion, was put forward by Japanese statistician Hiroji Akaike in 1973 [17]. SC refers to Schwartz criterion, also known as BIC. HQ refers to Hannan-Quinn criterion [18].

Table 2. The ADF test of the first-order difference sequence (no intercept term and no trend term.

\begin{tabular}{ccc}
\hline & t-Statistic & Prob. $^{*}$ \\
\hline Augmented Dickey-Fuller test statistic & -18.576 & 0.0000 \\
Test critical Values: $1 \%$ level & -2.569 & \\
$5 \%$ level & -1.941 & \\
$10 \%$ level & -1.616 & \\
\hline
\end{tabular}

of a unit root exists. And then $P$-value is small. All these indicate that the first-order difference sequence of the original sequence is stable, so $d=1$.

As can be clearly seen from Figure 3, the timing diagram of $D H$ fluctuates up and down around a constant value with a small fluctuation range. It can also be seen from Figure 4 that the autocorrelation coefficient rapidly decays to 0 . In summary, the original sequence is stable after the first-order difference, and the second-order difference test is no longer carried out.

As can be clearly seen from Figure 3, all $P$-values are less than 0.05 and close to 0 , so the original sequence is non-white noise, with a certain correlation and a law to follow. After lag order (lag) is 4, the partial autocorrelation coefficient 


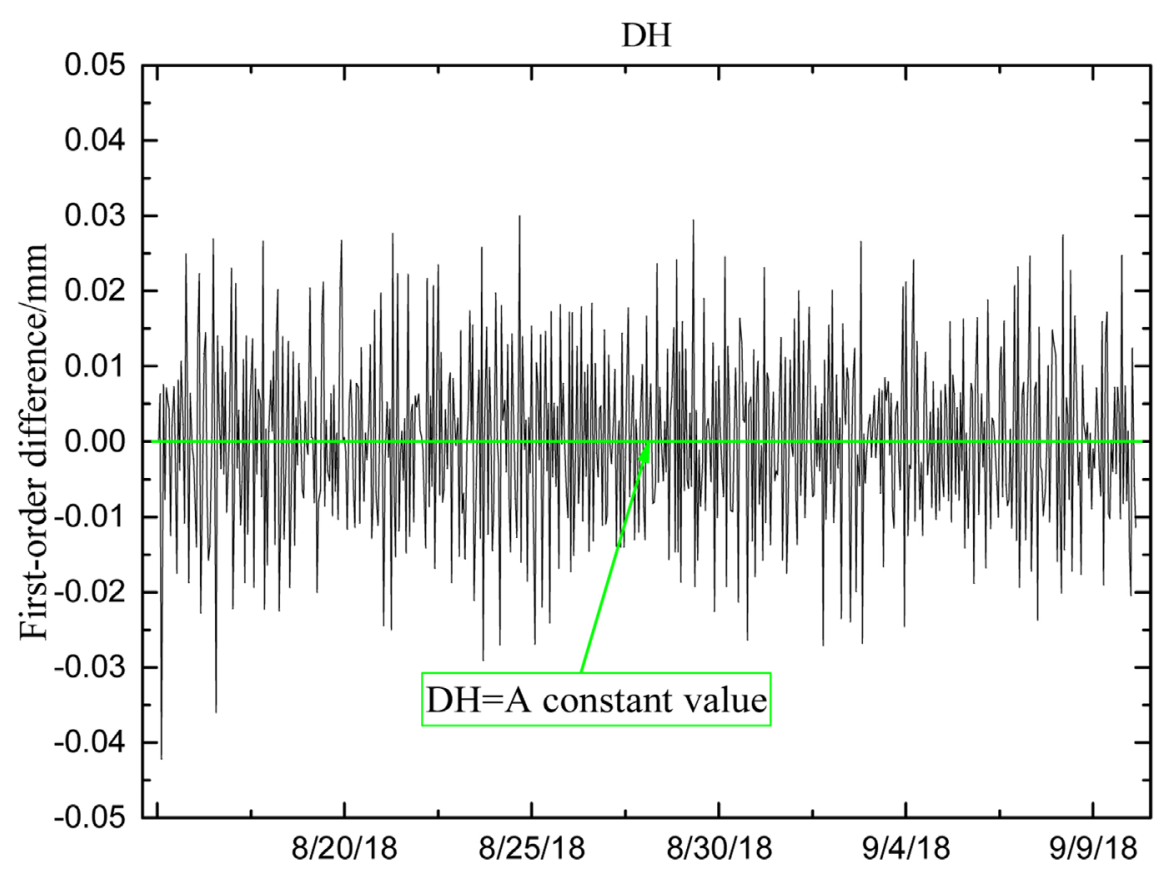

Figure 3. The first-order difference sequence diagram of the " $\mathrm{H}$ " dataset.

\begin{tabular}{|c|c|c|c|c|c|c|}
\hline Autocorrelation & Partial Correlation & & $A C$ & PAC & Q-Stat & Prob \\
\hline$\square_{1}$ & $\square_{\prime}^{\prime}$ & & -0.394 & -0.394 & 100.94 & 0.000 \\
\hline 1 & $\square_{1}$ & & -0.053 & -0.247 & 102.80 & 0.000 \\
\hline 1] & 다 & 3 & 0.008 & -0.145 & 102.85 & 0.000 \\
\hline 川 & 己। & 4 & -0.015 & -0.109 & 103.00 & 0.000 \\
\hline 小 & (1) & 5 & 0.012 & -0.062 & 103.09 & 0.000 \\
\hline 10 & 1 & 6 & -0.039 & -0.089 & 104.09 & 0.000 \\
\hline 川 & Li & 7 & -0.022 & -0.108 & 104.40 & 0.000 \\
\hline i) & 1 & 8 & 0.057 & -0.027 & 106.53 & 0.000 \\
\hline$\sqrt{1}$ & d & 9 & -0.064 & -0.089 & 109.23 & 0.000 \\
\hline ओ & 1 & 10 & 0.019 & -0.063 & 109.48 & 0.000 \\
\hline i & $1 / 1$ & 11 & 0.037 & -0.006 & 110.41 & 0.000 \\
\hline$\sqrt{11}$ & 1) & 12 & 0.023 & 0.042 & 110.75 & 0.000 \\
\hline$\|$ & 11 & 13 & -0.021 & 0.020 & 111.05 & 0.000 \\
\hline ती & 14 & 14 & -0.036 & -0.028 & 111.89 & 0.000 \\
\hline | & 川 & 15 & 0.012 & -0.024 & 111.99 & 0.000 \\
\hline 1 & 101 & 16 & -0.001 & -0.028 & 111.99 & 0.000 \\
\hline 川 & 10 & 17 & -0.022 & -0.042 & 112.30 & 0.000 \\
\hline 1 & 11 & 18 & 0.038 & 0.008 & 113.25 & 0.000 \\
\hline 101 & 101 & 19 & -0.042 & -0.041 & 114.45 & 0.000 \\
\hline $1 \mid 1$ & d & 20 & -0.006 & -0.058 & 114.48 & 0.000 \\
\hline 1 & 川 & 21 & 0.034 & -0.014 & 115.26 & 0.000 \\
\hline 川 & 101 & 22 & -0.019 & -0.031 & 115.51 & 0.000 \\
\hline $1 \mid 1$ & d & 23 & -0.007 & -0.050 & 115.54 & 0.000 \\
\hline 1) & 111 & 24 & 0.045 & 0.016 & 116.89 & 0.000 \\
\hline 14 & 川 & 25 & -0.042 & -0.023 & 118.10 & 0.000 \\
\hline
\end{tabular}

Figure 4. The first-order differential autocorrelation graph.

rapidly approaches to 0 , and the first-order difference sequence is preliminarily judged to be the fourth-order truncation of partial autocorrelation, so the $\operatorname{AR}(4)$ 
model can be tried to fit. When lag $=5$, the partial autocorrelation coefficient is at the edge of the confidence band of 2 times the standard deviation, so the $\mathrm{AR}(5)$ model can be tried to fit. For lag $=1$, the autocorrelation coefficient is not significantly zero, and for lag $=2,8$, it is on the edge of the confidence band of 2 standard deviations, so we can try to fit the MA(1), MA(2) and MA(8) models. Therefore, ARIMA $(4,1,1)$ and $\operatorname{ARIMA}(5,1,1)$ can be preliminarily fitted. Finally, it is found that $p$ may be equal to 4 and $q$ may be equal to 1,2 and 8 according to the model's order determination. Table 3 and Table 4 below are the comparison of estimated results and forecasted parameters of each fitting model respectively.

According to the judgment principle that the $P$-value is less than the significance level 0.05 and the smaller the result is, the more significant the result is (the model is better), the $P$-value values of $C, \operatorname{AR}(p)$ and $\operatorname{MA}(q)$ in Table 3 are compared to obtain the optimal $\operatorname{ARIMA}(3,1,1)$ model.

First, according to the "three criteria", AIC, SC and HQ value are relatively low, and the test statistics of each model in Table 4 are compared. It is concluded that $\operatorname{ARIMA}(3,1,1)$ has two minimum values (SC and $\mathrm{HQ}$ ). According to the principle of $\mathrm{F}$ distribution, the value of F-statistics is better, and the F statistic of ARIMA $(3,1,1)$ is obviously the largest, and the $P$-value is also less than the significance level of 0.05 . Therefore, $\operatorname{ARIMA}(3,1,1)$ was comprehensively judged as the optimal fitting model.

The formula of the model $\operatorname{ARIMA}(3,1,1)$ is derived [14] [19] as follows:

1) Because of $W_{t}=\hat{\alpha}+v_{t}$

2) Again,

Table 3. Comparing the $P$-values of the equations.

\begin{tabular}{ccccc}
\hline$P$-values/ $\left(10^{-2}\right)$ & $\begin{array}{c}\text { ARIMA } \\
(3,1,1)\end{array}$ & $\begin{array}{c}\text { ARIMA } \\
(4,1,1)\end{array}$ & $\begin{array}{c}\text { ARIMA } \\
(4,1,2)\end{array}$ & $\begin{array}{c}\text { ARIMA } \\
(4,1,8)\end{array}$ \\
\hline$C$ & 0 & 0 & 0 & 0 \\
$\operatorname{AR}(3)$ & 0.12 & 0.74 & 0 & 0.10 \\
$\operatorname{AR}(4)$ & - & 14.96 & 0.04 & 2.88 \\
MA(1) & 0 & 0 & 81.92 & 74.08 \\
MA(2) & - & - & 0 & 3.99 \\
MA(8) & - & - & - & 8.72 \\
\hline
\end{tabular}

Note: $C$ stands for constant; $A R$ represents the autoregressive process, and the lag order is denoted in brackets; $M A$ represents the sliding average process, and the brackets indicate the lag order.

Table 4. Comparing the precision indexes of various models.

\begin{tabular}{ccccc}
\hline Precision index & $\begin{array}{c}\text { ARIMA } \\
(3,1,1)\end{array}$ & $\begin{array}{c}\text { ARIMA } \\
(4,1,1)\end{array}$ & $\begin{array}{c}\text { ARIMA } \\
(4,1,2)\end{array}$ & $\begin{array}{c}\text { ARIMA } \\
(4,1,8)\end{array}$ \\
\hline AIC & -6.384 & -6.385 & -6.382 & -6.375 \\
SC & -6.349 & -6.343 & -6.333 & -6.285 \\
HQ & -6.370 & -6.368 & -6.363 & -6.340 \\
F-statistics & 62.787 & 50.921 & 42.410 & 21.887 \\
Prob (F-statistics) & 0.000 & 0.000 & 0.000 & 0.000 \\
\hline
\end{tabular}




$$
\begin{gathered}
\left(1-\hat{\rho}_{1} L-\hat{\rho}_{2} L^{2}-\hat{\rho}_{3} L^{2}\right) v_{t}=(1+\hat{\theta} L) \hat{e}_{t} \\
1-\hat{\rho}_{1} L-\hat{\rho}_{2} L^{2}-\hat{\rho}_{3} L^{2}
\end{gathered}
$$

3) If you multiply both sides of this equation by 11 , you get PI (1):

$$
W_{t}=\left(1-\hat{\rho}_{1}-\hat{\rho}_{2}-\hat{\rho}_{3}\right) \hat{\alpha}+\hat{\rho}_{1} w_{t-1}+\hat{\rho}_{2} w_{t-2}+\hat{\rho}_{3} w_{t-3}+\hat{e}_{t}+\hat{\theta} L \hat{e}_{t}
$$

4) The formula of $\operatorname{ARMA}(3,1)$ model is obtained by substituting the coefficient:

$$
\begin{aligned}
W_{t}= & 0.000061+0.381209 w_{t-1}+0.147211 w_{t-2}+0.127094 w_{t-3} \\
& +\hat{e}_{t}-0.994342 \hat{e}_{t}
\end{aligned}
$$

5) Then, making the $W_{t}=h_{t}-h_{t-1}$, and the formula of $\operatorname{ARIMA}(3,1,1)$ model is:

$$
\begin{aligned}
& \left(H_{t}-H_{t-1}\right)+0.381209\left(H_{t-2}-H_{t-1}\right) \\
& +0.147211\left(H_{t-3}-H_{t-2}\right)+0.127094\left(H_{t-4}-H_{t-3}\right) \\
& =0.000061+\hat{e}_{t}-0.994342 \hat{e}_{t}
\end{aligned}
$$

\begin{tabular}{|c|c|c|c|c|c|c|}
\hline Autocorrelation & Partial Correlation & & $A C$ & PAC & Q-Stat & Prob \\
\hline 川1 & $\|$ & 1 & -0.008 & -0.008 & 0.0448 & \\
\hline$\|$ & $\|$ & 2 & -0.020 & -0.020 & 0.3116 & \\
\hline اله & 1 & 3 & -0.029 & -0.029 & 0.8389 & \\
\hline 1 & 1) & 4 & 0.025 & 0.024 & 1.2380 & \\
\hline 1 & 1 & 5 & 0.026 & 0.026 & 1.6939 & 0.193 \\
\hline$川 1$ & $\| 1$ & 6 & -0.020 & -0.020 & 1.9641 & 0.375 \\
\hline 11 & 11 & 7 & 0.003 & 0.005 & 1.9705 & 0.579 \\
\hline 1) & 10 & 8 & 0.064 & 0.064 & 4.6530 & 0.325 \\
\hline 川1 & $\| 1$ & 9 & -0.014 & -0.015 & 4.7738 & 0.444 \\
\hline 1) & 1) & 10 & 0.053 & 0.056 & 6.6075 & 0.359 \\
\hline קו & קו & 11 & 0.089 & 0.095 & 11.778 & 0.108 \\
\hline 10 & 10 & 12 & 0.063 & 0.063 & 14.368 & 0.073 \\
\hline 11 & 11 & 13 & 0.002 & 0.009 & 14.371 & 0.110 \\
\hline ال & $\| 1$ & 14 & -0.032 & -0.022 & 15.028 & 0.131 \\
\hline 11 & 11 & 15 & -0.000 & -0.005 & 15.028 & 0.181 \\
\hline 111 & 11 & 16 & 0.016 & 0.006 & 15.199 & 0.231 \\
\hline 11 & 11 & 17 & -0.004 & -0.004 & 15.210 & 0.294 \\
\hline 111 & 11 & 18 & 0.011 & 0.007 & 15.297 & 0.358 \\
\hline 1 & الهו & 19 & -0.035 & -0.044 & 16.106 & 0.375 \\
\hline 11 & $\| 1$ & 20 & -0.004 & -0.016 & 16.117 & 0.445 \\
\hline יקו & 111 & 21 & 0.029 & 0.018 & 16.666 & 0.477 \\
\hline 11 & $\| 1$ & 22 & -0.008 & -0.022 & 16.705 & 0.543 \\
\hline 11 & $\| 1$ & 23 & 0.001 & -0.011 & 16.706 & 0.610 \\
\hline 1) & 10 & 24 & 0.047 & 0.049 & 18.215 & 0.573 \\
\hline 11 & 11 & 25 & 0.000 & 0.004 & 18.215 & 0.635 \\
\hline
\end{tabular}

\subsection{Diagnostic Testing of Models}

After determining the estimated ARMA model parameters, diagnostic tests are required to verify the adaptability of the fitting model. In this paper, Eviews time series analysis software is used to establish the autocorrelation graph of the residual error, and the residual error is tested by pure randomness. Figure 5 below is the result of $\operatorname{ARIMA}(3,1,1)$.

Figure 5. Residual correlation graph of the $\operatorname{ARMA}(3,1,1)$ model. 
As can be seen from Figure 5, the autocorrelation function values are almost within the confidence region of 0.95 . Secondly, all $P$-values are greater than 0.05 , indicating that the residuals are white noise and purely random. According to $\operatorname{ARIMA}(3,1,1)$ model fitting Figure 6, the fitting effect is good. By comprehensive judgment, the fitted $\operatorname{ARIMA}(3,1,1)$ model is effective.

\subsection{Application of Models}

In order to verify the applicability of the fitting model, the model ARIMA $(3,1,1)$ is used for forecasting. The dynamic forecasting was carried out first, and the results are shown in Figure 7 below.

The forecasted results were stored in the $D H$ sequence to make the dynamic forecasting fitting diagram of $D H$ and $D H F$, as shown in Figure 8. As can be seen from the figure, the trend line of dynamic forecasting results is basically a straight line without obvious fluctuation, indicating that the dynamic forecasting effect of this model is not good.

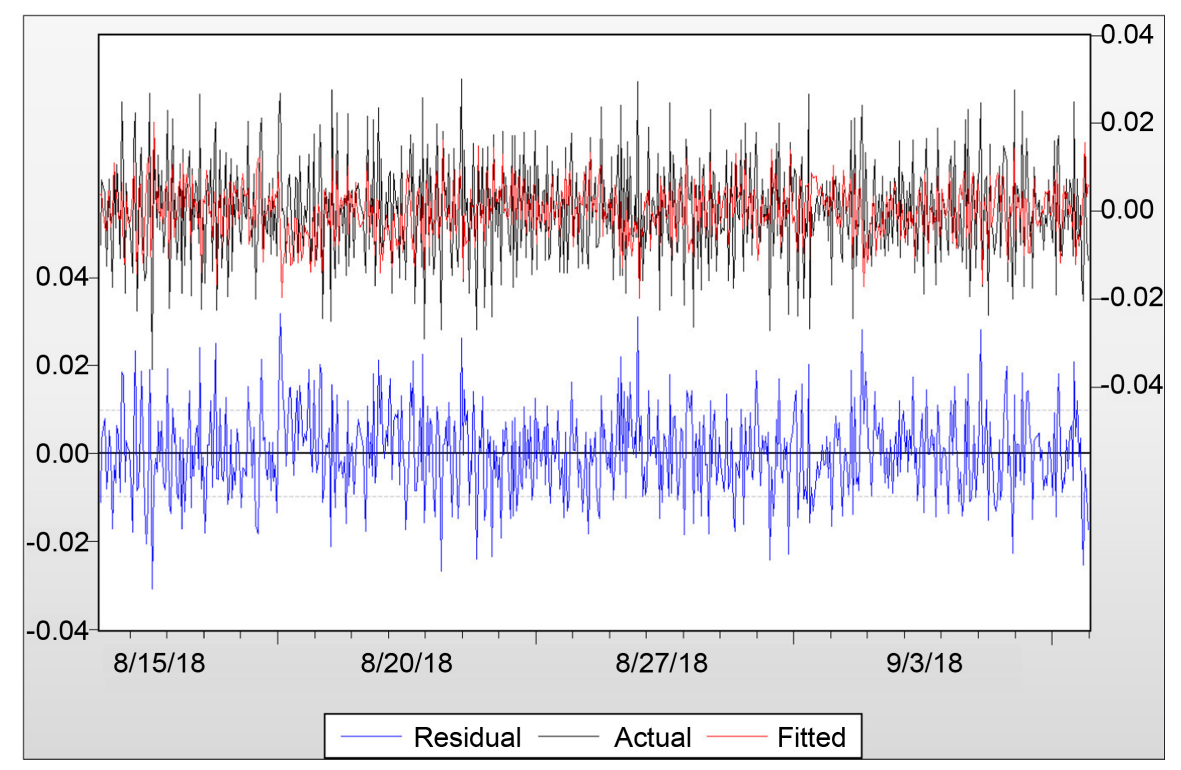

Figure 6. The fitting graph of the $\operatorname{ARMA}(3,1,1)$ model.

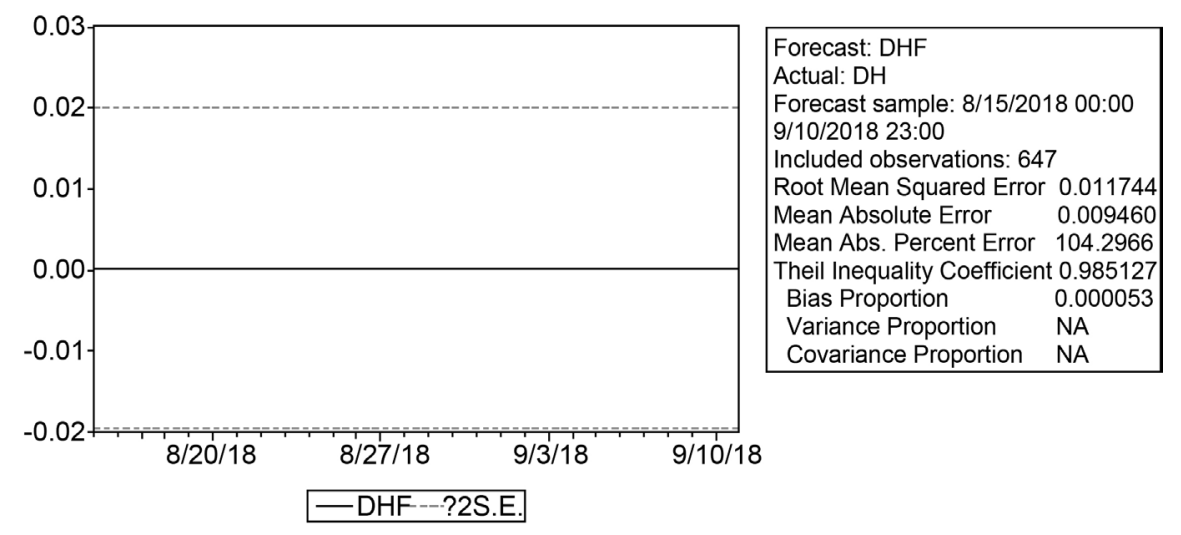

Figure 7. The sequence dynamic forecasting graph. 


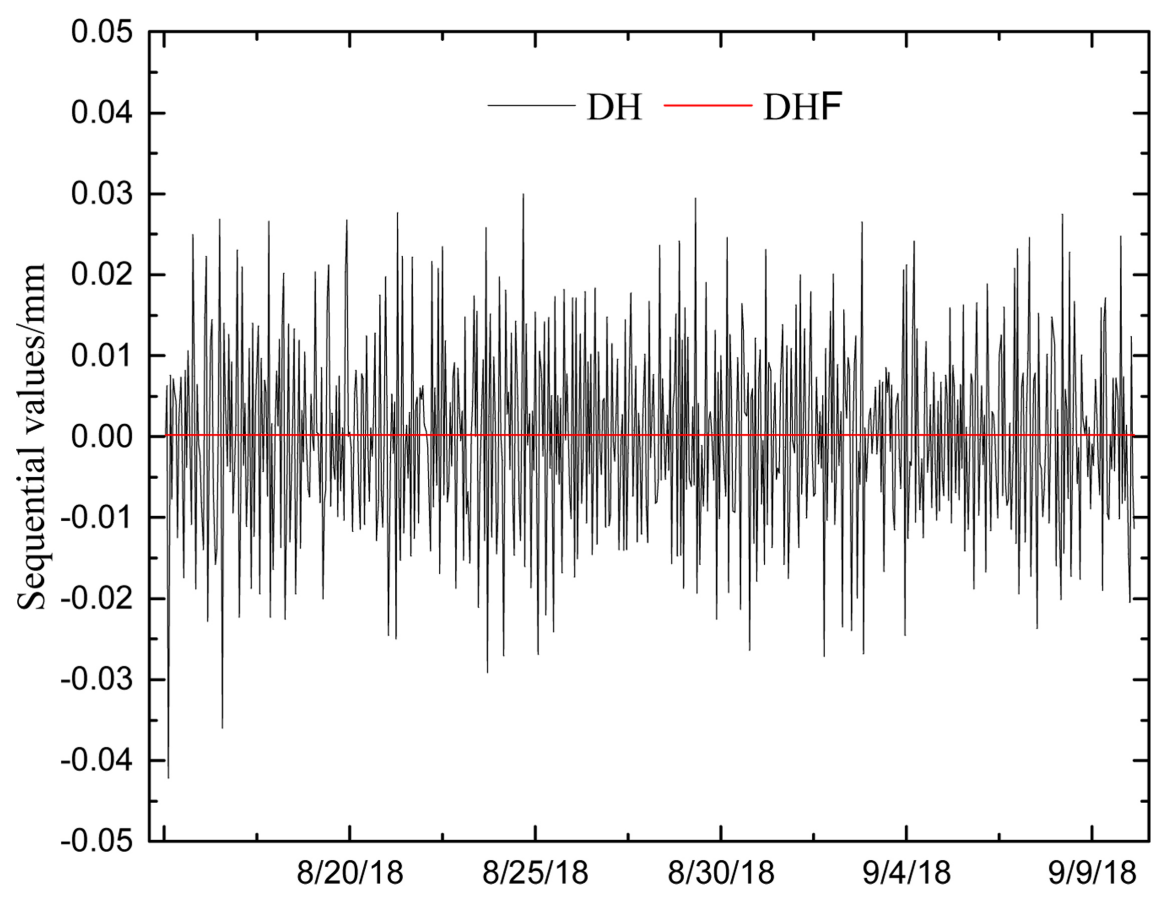

Figure 8. The dynamic forecasting fitting graph.

Secondly, the static forecasting is carried out, and its short-term forecasting can only be carried out step by step. The forecasting results are shown in Figure 9, which shows that the static forecasting effect of this model is quite ideal.

The forecasted values were stored in the $D H$ sequence to make the static forecasting fitting graph for $D H$ and $D H F$, as shown in Figure 10 below. It can be seen from the figure that the static forecasting effect of the model is better.

According to the existing forecasting value in $D H F$, the model $\operatorname{ARIMA}(3,1,1)$ formula can be used to deduce the forecasted value of the first phase reversely, and the forecasted value can be integrated into the original sequence, the same process can be used to obtain the forecasted value of the second phase, and so on until the $m(m=24)$ phase. Therefore, the limitations of the model for long-term forecasting are shown in Table 5.

where, the average relative error $\bar{e}$ is,

$$
\bar{e}=\frac{1}{n} \sum_{i=1}^{24} \frac{\left|h_{i}-h_{i}^{\prime}\right|}{h_{i}} \approx 1.73 \%
$$

where, $h_{i}$ and $h_{i}^{\prime}$ represent the actual value and the forecasted value respectively; $i$ represents the number of forecasting periods, $i=1,2, \cdots, 24 ; n=24$.

As can be seen from Table 5, the absolute error is relatively small, while the relative error is only $1.73 \%$. In Figure 11, the forecasted results are all within the confidence interval of 0.95 , and are basically consistent with the change trend of the actual value curve. Therefore, it is not difficult to draw the following conclusions from the forecasting results of the fitting model:

1) ARIMA model is feasible as a short-term forecasting model for deep horizontal displacement of slope soil. It can be seen from the forecasting fitting effect 


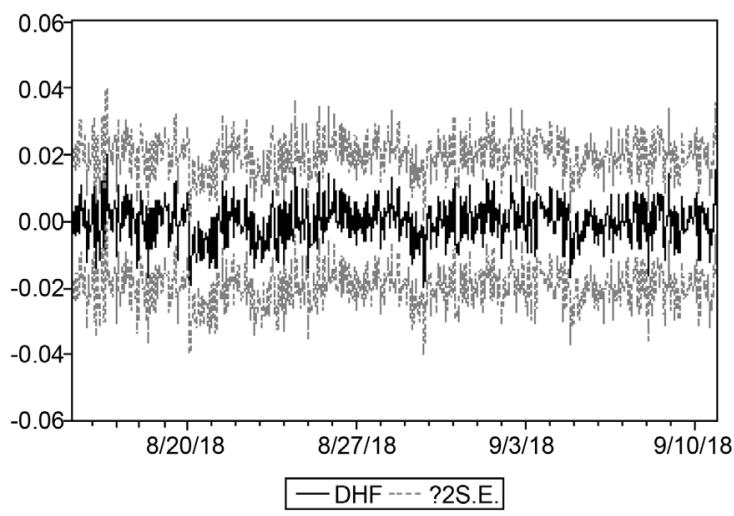

Forecast: DHF

Actual: $\mathrm{DH}$

Forecast sample: 8/15/2018 00:00 $9 / 10 / 201823: 00$ Adjusted sample: $\begin{array}{r}\text { 8/15/2018 04:00 } \\ 9 / 10 / 201823: 00\end{array}$

Included observations: 644

Root Mean Squared Error 0.009867

Mean Absolute Error $\quad 0.007850$

Mean Abs. Percent Error 467.0680

Theil Ans. Pelity Coefficient 0.553320

$\begin{array}{cc}\text { Theil Inequality Coefficient } 0.553320 \\ \text { Bias Proportion } & 0.000200\end{array}$

0.000200

Covariance Proportion $\quad 0.693610$

Figure 9. The sequence static forecasting graph.

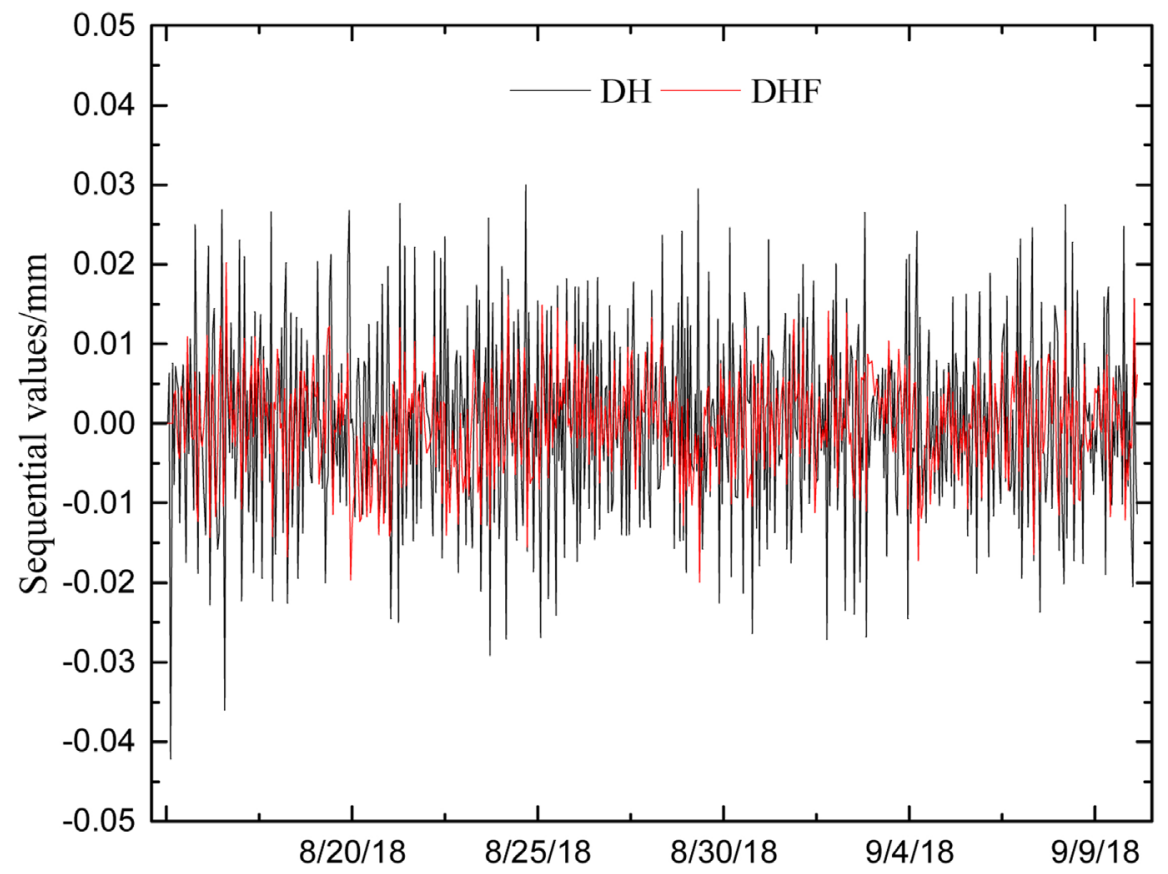

Figure 10. The static forecasting fitting graph.

diagram that the fitting effect is good, indicating that the original sequence contains the information of the "X-axis" direction of the deep horizontal displacement of the slope soil, and it is not difficult to see that the static forecasting effect is far better than the dynamic forecasting.

2) It is easy to generate the cumulative error when the static forecasted value is calculated by the model back-stepping. It is not difficult to see from the forecasting results of ARIMA $(3,1,1)$ in Table 5 that the average forecasting error of the first eight stages is about $0.69 \%$, the average forecasting error of the middle eight stages is $0.89 \%$, and the average forecasting error of the last eight stages is much larger than that of the first two stages, which is $1.41 \%$. This is because in order to forecast the second phase, the forecasted value of the first phase must be used for back-analysis, rather than the calculation of the real value of the first phase, and so on, so it is easy to produce cumulative error. This feature of static 


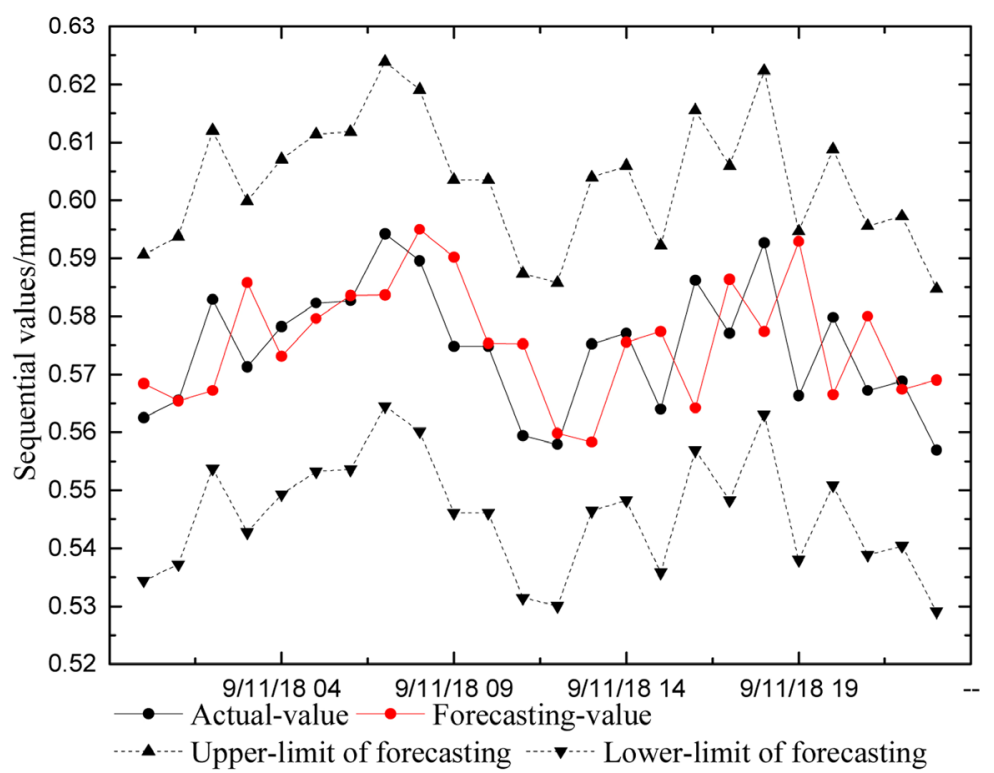

Figure 11. The static forecasting result.

Table 5. The forecasting results of model of $\operatorname{ARMA}(3,1,1)$.

\begin{tabular}{|c|c|c|c|c|}
\hline $\begin{array}{l}\text { Time serial } \\
\text { number }\end{array}$ & $\begin{array}{c}\text { Actual } \\
\text { value/ }\left(10^{-2} \cdot \mathrm{mm}\right)\end{array}$ & $\begin{array}{c}\text { Forecasting } \\
\text { value } /\left(10^{-2} \cdot \mathrm{mm}\right)\end{array}$ & $\begin{array}{c}\text { Absolute error } \\
(\%)\end{array}$ & $\begin{array}{c}\text { Relative error } \\
\text { (\%) }\end{array}$ \\
\hline 1 & 56.25 & 56.84 & 0.59 & 1.05 \\
\hline 2 & 56.55 & 56.54 & 0.01 & 0.02 \\
\hline 3 & 58.29 & 56.72 & 1.57 & 2.69 \\
\hline 4 & 57.13 & 58.58 & 1.45 & 2.54 \\
\hline 5 & 57.82 & 57.31 & 0.51 & 0.89 \\
\hline 6 & 58.23 & 57.96 & 0.27 & 0.47 \\
\hline 7 & 58.27 & 58.36 & 0.09 & 0.15 \\
\hline 8 & 59.42 & 58.37 & 1.05 & 1.77 \\
\hline 9 & 58.96 & 59.50 & 0.54 & 0.92 \\
\hline 10 & 57.48 & 59.02 & 1.55 & 2.69 \\
\hline 11 & 57.48 & 57.53 & 0.06 & 0.10 \\
\hline 12 & 55.94 & 57.52 & 1.59 & 2.84 \\
\hline 13 & 55.79 & 55.98 & 0.19 & 0.33 \\
\hline 14 & 57.52 & 55.83 & 1.69 & 2.94 \\
\hline 15 & 57.71 & 57.55 & 0.16 & 0.28 \\
\hline 16 & 56.40 & 57.74 & 1.35 & 2.39 \\
\hline 17 & 58.62 & 56.42 & 2.19 & 3.74 \\
\hline 18 & 57.71 & 58.64 & 0.93 & 1.60 \\
\hline 19 & 59.27 & 57.74 & 1.53 & 2.58 \\
\hline 20 & 56.63 & 59.29 & 2.66 & 4.69 \\
\hline 21 & 57.98 & 56.65 & 1.32 & 2.29 \\
\hline 22 & 56.72 & 58.00 & 1.28 & 2.26 \\
\hline 23 & 56.88 & 56.74 & 0.14 & 0.25 \\
\hline 24 & 55.69 & 56.90 & 1.21 & 2.17 \\
\hline \multicolumn{4}{|c|}{ Mean relative error } & 1.73 \\
\hline
\end{tabular}

Note: the forecasted time is "2018-09-11 00-2018-09-11 23", corresponding to the time serial number; Absolute-error $=\mid$ Actual-value - Forecasted-value $\mid{ }^{*} 100 \%$; Relative error $=(\text { Absolute-error/Actual-value })^{\star} 100 \%$. The actual value comes from the SQLsever database of Sichuan Shengtuo detection co., LTD. 
forecasting is not conducive to long-term forecasting, but overall, the relative error and average relative error of the forecasting results of the fitting model in this paper show that the absolute error of these 24 periods is very small, and the forecasting effect is relatively ideal.

3) The characteristic of time series forecasting itself is to extract useful information from the historical data of things to forecast their future development or trend. In this paper, other factors affecting the deep horizontal displacement of soil are only reflected by random terms, which is also a defect of the fitting model. In the empirical analysis, other factors affecting the deep horizontal displacement of soil cannot be controlled. Therefore, when selecting data, it is necessary to avoid major fluctuations caused by earthquakes and artificial construction as far as possible, so as to reduce the forecasting error.

\section{A New Method for the Forecasting and Management of Slope Stability}

Combined with the results of the whole empirical analysis, a theoretical method suitable for the forecasting and management of slope stability is proposed, which is a short-term static forecasting method of deep horizontal displacement of soil based on ARIMA model (ARIMA-soil displacement forecasting method), as shown in Figure 12.

ARIMA-soil displacement forecasting method, relies on the historical data of deep horizontal displacement monitoring of slope soil, builds ARIMA model by analyzing the original sequence, and makes short-term static forecasting. If the analysis results of the first phase forecasting are not harmful to the slope stability, the results of the first phase forecasting will be put into the original sequence for the second phase forecasting, and so on. On the other hand, if the analysis results of a certain period are not favorable to the slope stability, the monitoring should be strengthened and emergency measures should be prepared in advance. The application of this method can provide more basis for slope stability analysis and prevent slope safety accidents.

\section{Conclusions}

The forecasting of deep horizontal displacement of slope soil is a challenging

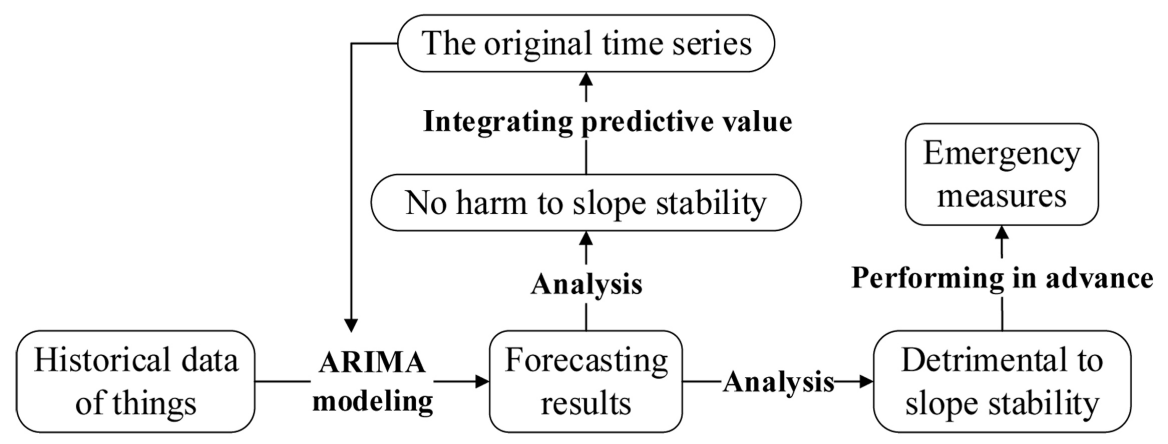

Figure 12. The workflow of the forecasting method. 
problem, but the forecasting of time series has always been considered as an effective means for statistical forecasting of trend growth (decrease) and time-varying fluctuation series. Because time series forecasting has a good short-term forecasting effect, although this paper only carries out short-term static forecasting of ARIMA model for time series of deep horizontal displacement of soil, theoretically time series can achieve long-term dynamic forecasting. In the empirical analysis of this paper, it can be seen from Figure 10 that the static forecasting results have a good fitting effect. It can be seen from Table 5 that both the absolute error and the average error obtained by the model forecasting are small. All these indicate that the ARIMA model is feasible as a short-term forecasting model for deep horizontal displacement of slope soil. Therefore, the use of the model ARIMA has certain reference value for this paper to seize the implementation opportunity of slope quality and safety management measures, analyze slope stability and prevent slope accidents.

Due to the time limitation, this paper only makes empirical analysis on the changes of some historical monitoring data of the deep horizontal displacement of slope soil, and when the sample data are changed, the structural parameters of the fitting model will also change accordingly, which indicates that the model is very sensitive to the changes of samples. At the same time, from the perspective of short-term static forecasting results, the fitting model still has the characteristics of short-term stability for the fluctuation pattern of soil displacement forecasting, but the forecasting accuracy also changes with the change of samples, so the conclusion may lack universality. In general, when using the ARIMA model to forecast the deep horizontal displacement of slope soil, it is better to forecast the historical data with stable development and change, no severe construction and large abnormal fluctuation caused by external factors such as emergencies. Finally, in order to better connect the empirical analysis conclusion with the slope management work, a new applied method of slope quality safety monitoring management, to ARIMA-soil displacement forecasting method is proposed.

In conclusion, this paper uses the ARIMA model and historical displacement value as sequence data to make short-term forecasting of the next 24 displacements, hoping that the results will be helpful for slope managers to strengthen slope safety management and prevent slope accidents. In addition, other forecasting methods can be considered to strengthen the attention to various influencing factors, such as slope structure, weather change, engineering construction, etc. Often these unstable factors also have important application value for the long-term trend of the deep horizontal displacement of slope soil.

\section{Conflicts of Interest}

The authors declare no conflicts of interest regarding the publication of this paper. 


\section{References}

[1] Wen, Y. and Zhu, J. (2018) On the Prediction for the Slope Stability Based on the SAPSO-ELM. Journal of Safety and Environment, 18, 2146-2150.

[2] Zhang, H. and Luo, Y. (2012) Prediction Model for Slope Stability Based on Artificial Immune Algorithm. Journal of China Coal Society, 37, 911-917.

[3] Sharma, R.K., Mehta, B.S. and Jamwal, C.S. (2013) Cut Slope Stability Evaluation of NH-21 along Nalayan-Gambhrola Section, Bilaspur District, Himachal Pradesh, India. Natural Hazards, 66, 249-270. https://doi.org/10.1007/s11069-012-0469-x

[4] He, Y. (2015) Several Key Techniques Application Research of Slope-Oriented Deformation Monitoring-Take Gong Jia-Fang Slope Monitoring for Example. Chongqing Jiaotong University, Chongqing.

[5] Zhai, X. (2015) Slope Deformation Monitoring Method Based on 3D Laser Scanning Technology. China University of Geosciences, Beijing.

[6] Mei, F. and Shi, X. (2018) Study on Slope Treatment Scheme and Stability of Shallow Buried Tunnel. Yunnan Water Power, 34, 165-168.

[7] Xue, X., Zhang, W. and Liu, H. (2008) Evaluation of Slope Stability Based on SOFM Neural Network. Rock and Soil Mechanics, 29, 2236-2240.

[8] Pieraccini, M., Casagli, N., Luzi, G., et al. (2010) Landslide Monitoring by Ground-Based Radar Interferometry: A Field Test in Valdarno (Italy). International Journal of Remote Sensing, 24, 1385-1391. https://doi.org/10.1080/0143116021000044869

[9] Barla, G., Antolini, F., Barla, M., Mensi, E. and Piovano, G. (2010) Monitoring of the Beauregard Landslide (Aosta Valley, Italy) Using Advanced and Conventional Techniques. Engineering Geology, 116, 218-235. https://doi.org/10.1016/j.enggeo.2010.09.004

[10] Gischig, V., Amann, F., Moore, J.R., et al. (2010) Composite Rock Slope Kinematics at the Current Randa Instability, Switzerland, Based on Remote Sensing and $\mathrm{Nu}$ merical Modeling. Engineering Geology, 118, 37-53. https://doi.org/10.1016/j.enggeo.2010.11.006

[11] Ruan, Z., Wang, Y. and Yang, H. (2012) Monitoring and Analysis of Slope Gauge of Two Deep Cut Landslides in Bailong Road. Journal of China \& Foreign Highway, $32,45-51$.

[12] Wang, Z. and Zhang, J. (2013) Landslides Monitoring Based on InSAR Technique. Journal of Geodesy and Geodynamics, 33, 87-91.

[13] Xu, M., Zhang, H., Li, H., et al. (2015) Open-Pit Slope Displacement Monitoring System Based on Measurement Robot. Science of Surveying and Mapping, 40, 38-41.

[14] Jonathan, D.C. and Kung-Sik, C. (2010) Time Series Analysis with Applications in R. 2nd Edition, Machinery Industry Press, Beijing, 63-70.

[15] Zhang, S., He, M., Luo, Y., et al. (2009) Modeling Virtual Dynamics for Pedestrian Microscopic Simulation. Journal of Transportation Systems Engineering and Information Technology, 9, 51-55.

[16] Wu, Y. and Wen, X. (2016) Short-Term Stock Price Forecast Based on ARIMA Model. Statistics \& Decision, 23, 83-86.

[17] Akaike, H. (1974) A New Look at the Statistical Model Identification. IEEE Transactions on Automatic Control, 19, 716-723. https://doi.org/10.1109/TAC.1974.1100705 
[18] Hannan, E.J. and Quinn, B.G. (1979) The Determination of the Order of an Autoregression. Journal of the Royal Statistical Society: Series B (Methodological), 41,190-195. https://doi.org/10.1111/j.2517-6161.1979.tb01072.x

[19] Gao, T. (2009) Econometric Analysis Methods and Modeling: EViews Applications and Examples. 2nd Edition, Tsinghua University Press, Beijing, 156-175. 